Article

\title{
Exploring Perceptions of Internet-Delivered Cognitive Behaviour Therapy among Public Safety Personnel: Informing Dissemination Efforts
}

\author{
Hugh C. McCall ${ }^{1,2, \dagger}$, Angelo P. Sison ${ }^{1,2, \dagger}$, Jody L. Burnett ${ }^{1,2}$, Janine D. Beahm ${ }^{1,2}$ a and \\ Heather D. Hadjistavropoulos $1,2, * \mathbb{D}$ \\ 1 Department of Psychology, University of Regina, 3737 Wascana Pkwy, Regina, SK S4S 0A2, Canada; \\ Hugh.McCall@uregina.ca (H.C.M.); angelo.sison93@gmail.com (A.P.S.); Jody.Burnett@uregina.ca (J.L.B.); \\ Janine.Beahm@uregina.ca (J.D.B.) \\ 2 PSPNET, University of Regina, 2 Research Drive, Regina, SK S4T 2P7, Canada \\ * Correspondence: Heather.Hadjistavropoulos@uregina.ca \\ + Denotes equal contributions.
}

Received: 12 July 2020; Accepted: 17 August 2020; Published: 19 August 2020

\begin{abstract}
Background Public safety personnel (PSP) experience high rates of mental health disorders but have limited access to treatment. To improve treatment access, there is a growing interest in offering internet-delivered cognitive behaviour therapy (ICBT) to PSP. As attitudes towards ICBT can both impact and inform ICBT implementation efforts, this study examines perceptions of ICBT among PSP who viewed a poster (a commonly used method of advertising ICBT) or a poster supplemented with a story of a PSP who benefitted from ICBT. Methods Participants $(N=132)$ from various PSP sectors were randomly assigned to view a poster or a poster and a story. Participants then completed an online survey assessing their perceptions of ICBT using both qualitative and quantitative questions. We used a mixed-methods approach to analyze the data. Results No differences in perceptions of ICBT were identified between the conditions. Ratings of credibility, treatment expectancy, anticipated treatment adherence, and acceptability suggested that PSP had positive perceptions of ICBT. Most participants (93\%) reported that they would access ICBT if they needed help with mental health concerns. Participants ranked therapist-guided ICBT as their second most preferred treatment, with psychologists ranked first. Female participants found ICBT more credible than male participants. More experienced PSP reported lower acceptability and anticipated adherence to ICBT. Conclusions The findings suggest that many PSP are likely to be receptive to ICBT even when a simple poster is used as a method of informing PSP of this treatment option. Further attention to improving the perceptions of ICBT among certain groups may be warranted.
\end{abstract}

Keywords: occupational injuries; internet; cognitive behavioural therapy; perception; telemedicine

\section{Introduction}

Public safety personnel (PSP) include border security officers, correctional officers, dispatch/communication workers, paramedics, firefighters, and police officers. A study investigating the mental health of Canadian PSP found that $44.5 \%$ had screened positive for one or more mental health disorders, which contrasts with the diagnostic rate of $10.1 \%$ in the general population [1]. Past research on various PSP sectors has shown that PSP in other countries also struggle with high rates of mental health problems (e.g., [2-4]). PSP are routinely confronted with traumatic stressors as part of their regular duties [5] and have been shown to deal with high levels of work demand and physical and psychological stressors [5]. They regularly work overtime, face close public scrutiny, take part in labour and management conflicts, and routinely experience harassment [5]. PSP have 
experienced high rates of trauma exposure and mental health disorders but have avoided seeking psychological services, due, in part, to concerns about mental health stigma [6]. Despite successful initiatives to provide resiliency training and reduce the stigma surrounding mental health problems, such as the Road to Mental Readiness for First Responders program [7], a recent study found that many Canadian PSP still report experiencing limited workplace support for mental health-related problems [8]. PSP face several other barriers to mental health services, including long waiting times, distance from services, concerns about privacy and confidentiality, and cost of treatment $[8,9]$.

Internet-delivered cognitive behaviour therapy (ICBT) is an alternative form of cognitive behaviour therapy (CBT) that is delivered online, often in the form of weekly lessons [10]. It can address common barriers to mental healthcare because it requires less therapist time than face-to-face treatments and can be accessed from virtually any location at any time [11]. Meta-analyses have found moderate to large effects of ICBT for several conditions, including major depression, generalized anxiety disorder, panic disorder, social anxiety disorder, and post-traumatic stress disorder [10]. Furthermore, there is mounting evidence that ICBT is effective when offered in routine practice $[12,13]$, and studies have shown that ICBT with therapist support is comparably efficacious to face-to-face therapy [10]. ICBT may benefit both individuals and organizations by decreasing the amount of time people are off work due to mental health-related disability [14].

Despite its effectiveness, research suggests that ICBT is not perceived as positively as face-to-face therapy. Participants in prior studies have acknowledged the advantages of ICBT, such as convenience, flexibility, and anonymity $[15,16]$, but have also perceived disadvantages such as low credibility and concerns about e-therapists' ability to display empathy or build trust [16]. Participants in several studies have overwhelmingly expressed a preference for face-to-face therapy over web-based interventions [15-17]. Perceptions of ICBT as less helpful than face-to-face therapy could limit the utility of ICBT for expanding access to mental health treatment because treatment expectations are related to treatment outcomes in psychotherapy [18].

Negative perceptions of ICBT appear to result, at least in part, from a lack of awareness of and knowledge about ICBT. In one study [19], participants indicated that they would have a $48 \%$ likelihood of using computerized CBT if they were depressed and would expect it to lead to a $35 \%$ improvement in symptoms, on average. After watching an educational video, participants indicated that they would have a $70 \%$ likelihood of using computerized CBT and would expect a $60 \%$ improvement in symptoms. In addition to its effect on intentions to use treatments, mental health knowledge is related to lower levels of stigma among PSP [20]. However, past research has not examined how stories impact the perceptions of ICBT. Compared to other means of relaying information, stories allow for a more personal connection to and a deeper understanding of the information [21]. Prior research has shown that stories can have positive influences on advertising services and health communication [22,23].

The present study addresses four main research questions. First, how do PSP perceive ICBT after viewing educational materials? Second, do PSP who learn about ICBT from a poster and a story perceive ICBT more favourably than PSP who learn about ICBT from a poster alone? Third, do certain demographic or clinical characteristics predict perceptions of ICBT? Fourth, how would PSP prefer for ICBT to be delivered, especially in terms of therapist support and, particularly, with regard to therapist guidance? Regarding our first research question, based on the literature on educating people about ICBT, discussed above, we hypothesized that our sample would report relatively positive perceptions of ICBT after viewing the educational materials. Regarding our second research question, we hypothesized that the group presented with the poster and story would report more positive perceptions of ICBT than the group presented with the poster only. Our third and fourth research questions were exploratory; we expected that further examination of PSP's perceptions of ICBT and the predictors of their perceptions could help inform education and implementation efforts (e.g., identifying specific client concerns about ICBT or groups who have elevated concerns). 


\section{Methods and Measures}

\subsection{Context}

In 2019, the Government of Canada initiated a national Action Plan entitled Supporting Canada's Public Safety Personnel: An Action Plan on Posttraumatic Stress Injuries [24]. Through this initiative, the Federal Government provided our research unit, PSPNET, with funding to develop and evaluate ICBT tailored for PSP. We began recruitment for the present study at approximately the same time as we launched our first ICBT program, called the PSP Wellbeing Course, in the province of Saskatchewan in January 2020. The PSP Wellbeing Course is based on a course initially developed at Macquarie University in Australia [25] and is designed to treat symptoms of depression, anxiety, and post-traumatic stress among PSP.

\subsection{Participants}

We recruited participants through email announcements sent to various PSP organizations across Saskatchewan, representing the following sectors: border security, corrections, communication/dispatch, emergency medical services, firefighting, and police. Invitations were also given in the form of unpaid advertisements on Facebook. We excluded 18 participants from data analysis for several reasons. Some participants $(n=7)$ indicated having previous experience with ICBT. One participant self-identified as a non-PSP, and another indicated that they had completed the survey twice. Lastly, some participants $(n=9)$ did not provide enough data to allow for meaningful data analyses. We analyzed data from 132 participants.

\subsection{Procedure}

Participants completed an online questionnaire, including demographic questions and questions about their recent mental health status. Participants were then randomly assigned to one of two groups. One group ( $n=61)$ was presented with a poster describing the PSP Wellbeing Course, and the other $(n=71)$ was presented with the same poster along with a client story about a PSP using ICBT. The ICBT poster included a general description of ICBT being offered to PSP in Saskatchewan, including an overview of what ICBT is, the evidence for its effectiveness, and how the course is delivered. The poster is displayed in Appendix A. The ICBT client story followed a PSP character named Sam, whose story was derived from those of various PSP interviewed in a separate study [8]. Sam's story described his experience using an ICBT program, including the knowledge, tools, and resources he received from ICBT and how they helped him manage his wellbeing and mental health as a PSP. The story is shown in Appendix B.

Both groups were then asked if they had any questions about ICBT based on the information. The group receiving the story was asked how much they related to the story and how much they expected other PSP would relate to the story. All participants completed a battery of questionnaires (described in detail below), including measures of the acceptability and credibility of ICBT and general help-seeking. We also administered questions pertaining to the participants' perceptions of ICBT (e.g., preferences for the level of therapist support, general likes and dislikes). At the end of the survey, participants were given the option to click on a link to pspnet.ca if they wanted to learn more about ICBT for PSP.

\subsection{Demographics Information}

Participants answered questions regarding age, gender, education level, relationship status, the size of the community they live in, ethnicity, employment, years of experience in PSP roles, past-year psychotropic medication use, past-year mental health treatment, and knowledge and experience of ICBT. 


\subsection{Patient Health Questionnaire 4-Item (PHQ-4)}

PHQ-4 [26] is a 4-item measure of depression and anxiety. Each item is answered on a 0-3 response scale, resulting in a total score ranging from 0 to 12 . PHQ-4 has demonstrated good internal consistency and construct validity [26]. The Cronbach's alpha for PHQ-4 was 0.87 in this study.

\subsection{PTSD Checklist for DSM-5 (PCL-2)}

PCL-2 [27] consists of two items related to symptoms of post-traumatic stress disorder (PTSD). Each item is answered on a 1-5 response scale. The measure has good specificity and sensitivity [27]. The Cronbach's alpha for PCL-2 in this study was 0.88 .

\subsection{Story Relatability}

Participants in the poster and story condition answered two questions about the relatability of the story: "Do you feel Sam's experiences are similar at all to your own?" and "Do you feel Sam's experiences are similar to any first responders/public safety personnel you know?". Participants responded using a $0-100 \%$ response scale.

\subsection{Treatment Acceptability and Adherence Scale (TAAS)}

TAAS [28] is a measure assessing the acceptability of a treatment and a respondent's anticipated adherence to that treatment. It is composed of ten questions, which respondents answer via a 7-point Likert scale. The items are summed with scores ranging from 10-70, with higher scores representing greater acceptability and anticipated adherence to the treatment in question [28]. The Cronbach's alpha for TAAS was 0.86 in this study.

\subsection{General Health Seeking Questionnaire (GHSQ)}

GHSQ [29] was used in this study to assess the respondent's perceived likelihood of seeking various sources of help. Response options ranged from 1 (extremely unlikely) to 7 (extremely likely). GHSQ has demonstrated good reliability and validity [29].

\subsection{Credibility and Expectations Questionnaire (CEQ)}

CEQ [30] is a questionnaire assessing the perceived credibility and expected outcomes of a treatment. It includes four items employing 9-point Likert scales and two items that respondents answer by selecting a percentage between zero and 100. We measured the credibility of treatment by calculating the mean of the first three items and expectancy by using the last item [31]. CEQ has demonstrated high internal consistency and good test-retest reliability [30]. The Cronbach's alpha for the credibility subscale of CEQ was 0.86 in this study.

\subsection{ICBT Treatment Support Preference Questionnaire}

This bespoke questionnaire consists of four items regarding preferences related to therapist support. First, we asked, "Do you think ICBT is a mental health support you would access if you needed help?" and participants selected "yes" or "no". We then asked participants how often they would like therapists to check in on their progress by email and how often they would like to send emails to e-therapists. Response options included "never", "only if I [request/feel like] it", "once a week", and "twice a week". Lastly, we asked participants to indicate whether they would prefer to complete ICBT with no therapist involvement, therapist involvement on demand, a therapist who checks the website and responds to questions once per week, or a therapist who does so twice per week.

\subsection{Treatment Preference}

We presented participants with 12 treatment options and asked them to rank the three options they would most prefer if they were dealing with depression, anxiety, or PTSD. The 12 options 
were as follows: ICBT with therapist support, ICBT with no therapist support, online counselling, psychologist, social worker, counsellor, doctor/GP, nurse practitioner, psychiatrist, self-help book, website information, and other (please specify). We also allowed participants to indicate if they "would not seek help from anyone".

\subsection{ICBT Likes and Dislikes}

Using open-ended text boxes, we asked participants what they liked and disliked about ICBT, about their perceptions of the advantages and disadvantages of ICBT, and whether they had any questions about ICBT.

\subsection{E-Therapy Assessment Measure (ETAM)}

ETAM [32] consists of three items related to the perceived effectiveness of ICBT, appropriateness of ICBT, and preference for ICBT compared with conventional face-to-face therapy. Responses are rated on a 5-point Likert scale ranging from "Disagree Strongly" to "Agree Strongly". We presented participants with an additional item using the same response scale: "In case of mental health problems, I would attend ICBT".

\subsection{Analysis}

We employed a mixed-methods approach to data analysis. We conducted all quantitative analyses using SPSS (version 23). We used descriptive statistics to examine the background characteristics of the sample, overall perceptions of ICBT, and the relatability of the story for those assigned to the poster and story condition. We compared conditions on demographic and clinical characteristics using $t$-tests and chi-square analyses. In order to test our hypothesis that participants presented with the poster and story would report more positive perceptions of ICBT than participants presented with the poster alone, we conducted an ANOVA to examine whether the perceptions of ICBT (measured via CEQ, ETAM, and TAAS) differed between conditions. We also conducted three linear regressions to examine the predictors of the perceived credibility (measured via CEQ), treatment expectations (measured via CEQ), and acceptability and anticipated adherence (measured via TAAS) of ICBT. Predictors inputted into each regression analysis included age, gender, size of home community, PSP sector, years of experience as a PSP, education level, familiarity with ICBT, relationship status, medication, mental health treatment, and PHQ-4 and PCL-2 scores. We used descriptive statistics to examine how ICBT ranked in preference compared to other treatments and how PSP indicated they would prefer ICBT to be delivered.

We supplemented these quantitative analyses with qualitative analyses to further explore PSP's perceptions of ICBT. Specifically, we used an inductive qualitative content analysis [33] to examine participants' responses concerning their likes and dislikes of ICBT and their questions about ICBT. First, the author A.S. reviewed participants' responses to the open-ended questions and developed a coding guide for participants' perceived likes and dislikes of ICBT. Next, A.S. and authors H.M. and J.D.B. reviewed and refined the initial coding guide. All authors then met to finalize the coding guide, and H.M. and J.D.B. recoded several responses and reviewed all data to ensure it was coded consistently with the finalized coding guide.

\subsection{Power Analysis}

We conducted power analyses using $G^{*}$ Power 3 [34]. For our multiple regression analysis, given an alpha of 0.05 , a power level of 0.80 , and 12 predictors, and assuming a medium effect size of $f^{2}=0.15$, we required a sample of 127 participants. For the ANOVA analysis, given an alpha of 0.05 , a power level of 0.80 , and two conditions, and assuming a medium effect size of $f=0.25$, we required a sample size of 128 . 


\section{Results}

\subsection{Participant Characteristics}

Participants had an average age of $39.90(S D=9.54)$ years. The gender ratio was relatively evenly split between male and female PSP (male $n=68 ; 52 \%$; female $n=62 ; 47 \%$; nonbinary $n=2 ; 2 \%$ ). Approximately half the participants $(n=70,53 \%)$ reported living in communities with a population over 100,000 and half $(n=62,47 \%)$ in communities under 100,000. Most PSP were married $(n=89$, $67 \%)$, had attained a postsecondary degree $(n=85,64 \%)$, and identified themselves as white $(n=119$, $90 \%)$. Only 5 (4\%) reported not being employed at the time of survey completion, and most $(n=86$, $65 \%$ ) had 10 or more years of experience working as PSP. The sample included PSP from various sectors: border security $(n=10,8 \%)$, corrections $(n=18,14 \%)$, communications/dispatch $(n=8,6 \%)$, emergency medical services $(n=41,31 \%)$, firefighting $(n=20,15 \%)$, and police $(n=35,27 \%)$.

About a quarter of participants $(n=32,24 \%)$ reported using medication for a mental health problem within the previous year, and nearly half $(n=59,45 \%)$ reported receiving professional help for a mental health problem within the previous year. When asked how familiar they were with ICBT, many participants $(n=56,42 \%)$ indicated that they had at least "a little knowledge" of it. Participants had a mean PHQ-4 score of $3.4(S D=3.0)$, and most $(n=73,55 \%)$ had clinically significant scores (i.e., scores greater than 3 [26]). The mean PCL-2 score was $4.25(S D=2.01)$, and most participants ( $n=81,61 \%$ ) had clinically significant scores (i.e., scores greater than 4 [27]). Chi-square analyses and $t$-tests revealed no differences between conditions on any demographic or clinical characteristics ( $p$ s $>$ 0.05). The demographic and clinical characteristics, collapsed across conditions, are summarized in Table 1.

\subsection{Quantitative Analyses}

To test our hypothesis that participants presented with the poster and story would report more positive perceptions of ICBT than participants presented with the poster alone, we used an ANOVA to compare the conditions on attitudes towards ICBT. The results indicated there were no differences on the expectancy subscale of CEQ $(F(1,130)=0.198, p=0.657)$, the credibility subscale of CEQ $(F(1$, $130)=0.406, p=0.525), \operatorname{ETAM}(F(1,130)=0.001, p=0.979)$, or $\operatorname{TAAS}(F(1,130)=0.006, p=0.94)$. Given that demographic and clinical characteristics, credibility, expectancy, and e-therapy measure scores did not differ across conditions, both conditions were collapsed for the remainder of the analyses.

To test our hypothesis that participants would report relatively positive perceptions of ICBT, we calculated descriptive statistics to examine participants' attitudes towards ICBT. Across both conditions, participants provided mean scores of 18.52 on the credibility subscale of CEQ $(S D=4.87), 53.79$ on the expectancy subscale of CEQ $(S D=22.16), 9.20$ on ETAM $(S D=3.19)$, and 51.86 on TAAS $(S D=9.42)$. On average, participants randomly assigned to review the story reported finding it to be $50 \%$ similar to their own experiences $(S D=30 \%)$ and $73 \%$ similar to the experiences of other PSP they knew $(S D=28 \%)$. When participants were asked to rank their top three most preferred sources of treatment, psychologists were most frequently ranked in the top three $(n=77,58 \%)$, followed by therapist-guided ICBT $(n=68,52 \%)$, counsellors $(n=50,38 \%)$, and doctors $(n=47,36 \%)$. See Table 2 for details. Results from the ICBT Therapist Support Preferences Questionnaire indicated that most participants $(n=123$, 93\%) would access ICBT if they needed help. 
Table 1. Participant demographic and clinical characteristics.

\begin{tabular}{|c|c|}
\hline Participant Characteristics & All Participants $(N=132)$ \\
\hline \multicolumn{2}{|c|}{ Continuous variables, $M(S D)$} \\
\hline Age & $39.90(9.54)$ \\
\hline PHQ-4 total score & $3.49(3.05)$ \\
\hline PCL-2 total score & $4.26(2.02)$ \\
\hline \multicolumn{2}{|c|}{ Categorical variables, $n(\%)$} \\
\hline \multicolumn{2}{|l|}{ Gender } \\
\hline Male & $68(52)$ \\
\hline Female & $62(47)$ \\
\hline Nonbinary & $2(2)$ \\
\hline \multicolumn{2}{|l|}{ Community size } \\
\hline$<100,000$ & $62(47)$ \\
\hline$>100,000$ & $70(53)$ \\
\hline \multicolumn{2}{|l|}{ Relationship status } \\
\hline Not married/partnered & $43(32)$ \\
\hline Married/partnered & $89(67)$ \\
\hline \multicolumn{2}{|l|}{ Ethnicity } \\
\hline Ethnic minority & $13(10)$ \\
\hline White & $119(90)$ \\
\hline \multicolumn{2}{|l|}{ Employment status } \\
\hline Not working & $5(4)$ \\
\hline Working & $126(94)$ \\
\hline \multicolumn{2}{|l|}{ Years of PSP experience } \\
\hline $0-10$ years & $45(34)$ \\
\hline $10+$ years & $86(65)$ \\
\hline \multicolumn{2}{|l|}{ Highest level of education } \\
\hline No degree & $47(36)$ \\
\hline Degree & $85(65)$ \\
\hline \multicolumn{2}{|l|}{ PSP sector } \\
\hline Border security & $10(8)$ \\
\hline Corrections & $18(14)$ \\
\hline Dispatch/communications & $8(6)$ \\
\hline Fire & $20(15)$ \\
\hline Paramedicine & $41(31)$ \\
\hline Police & $35(27)$ \\
\hline \multicolumn{2}{|c|}{ Medication for mental health in last 12 months } \\
\hline Yes & $32(24)$ \\
\hline No & $100(76)$ \\
\hline \multicolumn{2}{|c|}{ Professional help for mental health in last 12 months } \\
\hline Yes & $59(45)$ \\
\hline No & $73(55)$ \\
\hline \multicolumn{2}{|l|}{ Familiarity with ICBT } \\
\hline Not familiar & $76(58)$ \\
\hline Familiar & $56(42)$ \\
\hline \multicolumn{2}{|l|}{ PHQ-4 } \\
\hline Not clinically significant (less than 3) & $59(45)$ \\
\hline Clinically significant ( 3 or greater) & $73(55)$ \\
\hline \multicolumn{2}{|l|}{ PCL-2 } \\
\hline Not clinically significant (less than 4) & $51(39)$ \\
\hline Clinically significant (4 or greater) & $81(61)$ \\
\hline
\end{tabular}

Note. PHQ-4 = Patient Health Questionnaire 4-Item; PCL-2 = PTSD Checklist for DSM-5; PSP = public safety personnel; ICBT $=$ internet-delivered cognitive behaviour therapy. 
Table 2. Mental health treatment preferences among public safety personnel.

\begin{tabular}{|c|c|c|c|c|c|}
\hline & Treatment Preference & $\begin{array}{l}\text { Most Preferred } \\
\text { Treatment, } n(\%)\end{array}$ & $\begin{array}{c}\text { Second Most } \\
\text { Preferred } \\
\text { Treatment, } n(\%)\end{array}$ & $\begin{array}{c}\text { Third Most } \\
\text { Preferred } \\
\text { Treatment, } n(\%)\end{array}$ & $\begin{array}{c}\text { One of Three } \\
\text { Most Preferred } \\
\text { Treatments, } n(\%)\end{array}$ \\
\hline 1. & Psychologist & $45(34)$ & $22(17)$ & $10(8)$ & $77(58)$ \\
\hline 2. & ICBT with therapist assistance & $20(15)$ & $19(14)$ & $29(22)$ & $68(52)$ \\
\hline 3. & Counsellor & $17(13)$ & $15(11)$ & $18(14)$ & $50(38)$ \\
\hline 4. & Doctor & $12(9)$ & $15(11)$ & $20(15)$ & $47(36)$ \\
\hline 5. & Psychiatrist & $7(5)$ & $15(11)$ & $8(6)$ & $30(23)$ \\
\hline 6. & ICBT with no therapist assistance & $7(5)$ & $11(8)$ & $7(5)$ & $25(19)$ \\
\hline 7. & Online counselling & $2(2)$ & $9(7)$ & $10(8)$ & $21(16)$ \\
\hline 8. & Self-help book & $2(2)$ & $5(4)$ & $9(7)$ & $16(12)$ \\
\hline 9. & Website Information & $3(2)$ & $5(4)$ & $5(4)$ & $13(10)$ \\
\hline 10. & Other (e.g., priest, significant other) & $6(5)$ & $2(2)$ & $1(1)$ & $9(7)$ \\
\hline 11. & Social Worker & $1(1)$ & $4(3)$ & $2(2)$ & $7(5)$ \\
\hline 12. & Nurse Practitioner & $1(1)$ & $2(2)$ & $3(2)$ & $6(5)$ \\
\hline
\end{tabular}

To explore our research question concerning possible predictors of perceptions of ICBT, we conducted three regression analyses. Clinical and demographic variables did not significantly predict scores on the expectancy subscale of CEQ $\left(R^{2}=0.10, F(13,113)=0.98, p=0.48\right)$, but they did significantly predict scores on the credibility subscale of CEQ $\left(R^{2}=0.20, F(13,113)=0.2 .19, p=0.014\right)$. This second regression showed that identifying as female significantly predicted higher scores on the credibility subscale of CEQ $(\beta=0.29, t(113)=3.26, p=0.001)$. Lastly, a third regression showed that the clinical and demographic variables predicted TAAS total scores $\left(R^{2}=0.20, F(13,113)=2.20, p=0.014\right)$. In this regression, years of experience as a PSP negatively predicted TAAS total scores $(\beta=-0.23$, $t(113)=-2.22, p=0.03)$. The results of these regressions are summarized in Table 3 below.

Table 3. Summary of regression models and statistically significant predictors.

\begin{tabular}{|c|c|c|c|c|c|c|c|c|}
\hline \multirow{2}{*}{ Model and Significant Predictors } & \multirow{2}{*}{$B$} & \multicolumn{2}{|c|}{$95 \%$ CI for $B$} & \multirow{2}{*}{$S E B$} & \multirow{2}{*}{$\beta$} & \multirow{2}{*}{$p$} & \multirow{2}{*}{$R^{2}$} & \multirow{2}{*}{$\Delta R$} \\
\hline & & Lower Limit & Upper Limit & & & & & \\
\hline Predicting CEQ (expectancy) & & & & & & 0.48 & 0.10 & 0.00 \\
\hline Constant & 75.04 & 33.33 & 116.76 & 21.06 & & 0.001 & & \\
\hline Predicting CEQ (credibility) & & & & & & 0.014 & 0.20 & 0.11 \\
\hline Constant & 17.64 & 9.18 & 26.10 & 4.27 & & 0.001 & & \\
\hline Identification as female & 2.72 & 1.07 & 4.37 & 0.83 & 0.29 & $<0.001$ & & \\
\hline Predicting TAAS & & & & & & 0.014 & 0.20 & 0.11 \\
\hline Constant & 59.71 & 43.48 & 75.95 & 8.19 & & $<0.001$ & & \\
\hline Years of experience as PSP & -4.29 & -8.13 & -0.46 & 1.94 & -0.23 & 0.03 & & \\
\hline
\end{tabular}

Note: $\mathrm{CI}=$ confidence interval; $S E$ = standard error; $\mathrm{CEQ}=$ Credibility and Expectations Questionnaire;

TAAS = Treatment Acceptability and Adherence Scale; PSP = public safety personnel. Each model included

12 predictor variables, as described above- - this table shows only statistically significant predictors for each model.

Results from the ICBT Therapist Support Preferences Questionnaire addressed our research question concerning PSP's preferences for the delivery of ICBT. Many expressed a preference to have a therapist check in on their progress by email once $(n=84,64 \%)$ or twice $(n=15,11 \%)$ per week, although approximately one in four $(n=32,24 \%)$ indicated that they would prefer therapists to be available upon request. Similarly, most participants indicated that they would prefer to have a therapist monitor their progress and respond to questions once $(n=55,42 \%)$ or twice $(n=31,23 \%)$ per week, and one in three indicated a preference for no monitoring and guidance on demand instead $(n=42$, $32 \%)$. About half of our participants $(n=66,50 \%)$ responded that they would email a provider "only if [they] feel like it", followed by once per week $(n=52,39 \%)$. Few $(n=9,7 \%)$ indicated that they would email their therapists twice per week.

\subsection{Qualitative Analyses}

When invited to ask questions about ICBT, several participants $(n=7,5 \%)$ asked logistical questions. For example, participants asked what would happen if users did not complete therapy, how 
many sessions users typically complete per week, and how long it takes to complete the program. Participants also asked questions about anonymity $(n=1,1 \%)$ and costs $(n=1,1 \%)$.

The most common "like" identified with ICBT was accessibility $(n=111,84 \%)$. The theme of accessibility was subcategorized into seven categories, as presented in Table 4 . The most frequently endorsed subcategories were convenience $(n=25,19 \%)$ and the time-flexible nature of ICBT $(n=37$, $28 \%)$. The two most common likes after accessibility were anonymity/privacy $(n=16,12 \%)$ and that ICBT provides information/techniques/advice on mental health (e.g., "covers a large range of issues"; $n=14$, $11 \%)$. The most common "dislike" was the lack of face-to-face interaction with a therapist or the belief that ICBT would feel impersonal ( $n=41,31 \%)$. Other participants expressed concerns about the effectiveness of ICBT $(n=11,8 \%)$ or issues related to clients' accountability and motivation $(n=14,11 \%)$.

Table 4. PSP likes and dislikes of ICBT.

\begin{tabular}{|c|c|c|c|}
\hline \multirow{2}{*}{ Theme } & Poster Only, & Poster and Story, & Total, \\
\hline & $n(\%)$ & $n(\%)$ & $n(\%)$ \\
\hline \multicolumn{4}{|l|}{ Likes } \\
\hline \multicolumn{4}{|l|}{ Accessibility } \\
\hline Time flexible & $16(12)$ & $21(16)$ & $37(28)$ \\
\hline Convenience & $8(6)$ & $17(13)$ & $25(19)$ \\
\hline No transportation required & $8(6)$ & $12(9)$ & $16(12)$ \\
\hline General reference to accessibility & $5(4)$ & $5(4)$ & $10(8)$ \\
\hline Comfort with technology & $4(3)$ & $6(5)$ & $10(8)$ \\
\hline No need to schedule or wait for appointment & $3(2)$ & $4(3)$ & $7(5)$ \\
\hline Enable more people to seek help & $5(4)$ & $1(1)$ & $6(5)$ \\
\hline Anonymity/privacy & $11(8)$ & $5(4)$ & $16(12)$ \\
\hline Provides information/techniques/advice & $8(6)$ & $6(5)$ & $14(11)$ \\
\hline Did not identify any likes & $7(5)$ & $1(1)$ & $8(6)$ \\
\hline Complements existing treatments & 0 & $4(3)$ & $4(3)$ \\
\hline Effective & 0 & $3(2)$ & $3(2)$ \\
\hline Therapist guidance & $2(2)$ & $1(1)$ & $3(2)$ \\
\hline Brief & 0 & $2(2)$ & $2(2)$ \\
\hline Low cost/no cost & $1(1)$ & $1(1)$ & $2(2)$ \\
\hline Breadth of course & $1(1)$ & 0 & $1(1)$ \\
\hline Interesting & 0 & $1(1)$ & $1(1)$ \\
\hline Tailored to PSP & $1(1)$ & 0 & $1(1)$ \\
\hline Team review approach & 0 & $1(1)$ & $1(1)$ \\
\hline \multicolumn{4}{|l|}{ Dislikes } \\
\hline No dislikes identified & $23(17)$ & $23(17)$ & $46(35)$ \\
\hline \multicolumn{4}{|l|}{ Concerns about } \\
\hline Impersonality or lack of face-to-face contact & $20(15)$ & $21(16)$ & $41(31)$ \\
\hline Accountability and motivation & $5(4)$ & $9(7)$ & $14(11)$ \\
\hline Effectiveness & $8(6)$ & $3(2)$ & $11(8)$ \\
\hline Demands of treatment tasks & $1(1)$ & $4(3)$ & $5(4)$ \\
\hline Standardized nature of treatment & $5(4)$ & 0 & $5(4)$ \\
\hline Crisis management & $1(1)$ & $1(1)$ & $2(2)$ \\
\hline Eligibility & $2(2)$ & 0 & $2(2)$ \\
\hline Ability to trust e-therapists & 0 & $1(1)$ & $1(1)$ \\
\hline Confidentiality & $1(1)$ & 0 & $1(1)$ \\
\hline Triggering negative emotions & 0 & $1(1)$ & $1(1)$ \\
\hline
\end{tabular}

Note: ICBT = internet-delivered cognitive behaviour therapy; PSP = public safety personnel. 


\section{Discussion}

\subsection{Principal Findings and Implications}

Overall, as hypothesized, participants reported positive perceptions of ICBT. Most participants $(93 \%)$ indicated that if they needed help with mental health concerns, they would use ICBT. Across conditions, participants' responses to CEQ and TAAS indicated that they perceived ICBT as moderately credible and acceptable and expected adequate adherence and moderate symptom improvement. Mean scores on CEQ were comparable to those of primary care patients and postsecondary students who were asked about their perceptions of ICBT in previous studies, and mean TAAS scores were slightly higher $[35,36]$. It is important to highlight that therapist-guided ICBT was the second most preferred treatment. It was included among the three most preferred treatments for $52 \%$ of participants, closely following psychologists, who were included among the three most preferred treatments by $58 \%$ of participants. This finding contrasts with recent studies in which participants have shown strong preferences for other treatments over ICBT [15-17]. The results of the ANOVA did not support our hypothesis that receiving additional information about ICBT through a story would result in more positive perceptions of ICBT compared to the group that only received an ICBT poster.

Participants provided useful feedback on how they would like ICBT to be delivered. Only 19\% of participants ranked unguided ICBT as one of their three most preferred treatment options, and only $5 \%$ ranked it as their most preferred option, suggesting that therapist guidance is important to most PSP. Prior research has shown that the general public also prefers guided ICBT to unguided ICBT [37]. Most participants $(65 \%)$ indicated a preference for therapists to check in on their progress at least once a week, although approximately one in three (32\%) expressed a preference for optional therapist guidance over regular therapist check-ins.

We found two statistically significant predictors of perceptions of ICBT in our regression analyses. First, we found that a greater number of years of experience working as a PSP predicted lower acceptability of and anticipated adherence to ICBT on TAAS. Second, we found that female participants found ICBT more credible than male participants on CEQ. This second finding is consistent with previous literature showing that females are more likely to report positive perceptions of psychotherapy [38]. However, other studies that have examined participant attitudes toward ICBT did not find that gender predicted attitudes [35,39]. Likewise, previous studies have found that several other demographic and clinical variables have predicted attitudes towards ICBT. For example, one study [17] showed that older age, previous experience with Internet-based therapy, and confidence with computers, technology, and the internet predicted intentions to use internet-based therapy in the future. A recent study conducted in Saskatchewan found that higher perceived need for treatment, lower self-stigma regarding help-seeking, lower access to other forms of care, and lower computer anxiety predicted greater interest in ICBT [40]. Another recent study showed that among students, greater depression predicted lower acceptability and anticipated adherence on TAAS [36].

The most common perceived advantages of ICBT were convenience, the time-flexible nature of ICBT, the fact that no transportation is required, and anonymity/privacy. These findings are consistent with previous studies in which participants have recognized that ICBT can address common barriers to treatment, such as time, location, and anonymity [15]. The most common dislikes of ICBT were the lack of face-to-face interaction with a therapist and ICBT feeling impersonal. Participants also expressed concerns about the effectiveness of ICBT and the issue of client accountability and motivation. The participants' concerns with ICBT were similar to those expressed by the general population in past research $[15,17,41]$. Few participants indicated that they had questions about ICBT. The questions participants asked were generally logistical in nature (e.g., about anonymity, costs, and timeframe). These questions may indicate important areas of curiosity or concern that ICBT researchers or providers should address when preparing educational information regarding ICBT for PSP. 
Taken together, these findings have three important implications. First, they suggest that ICBT may be particularly well suited to PSP. The finding that therapist-guided ICBT was the second most preferred treatment was striking because prior research has shown that the general population strongly prefers other mental health treatments to ICBT [15-17]. The participants' positive perceptions of ICBT suggest that ICBT may have good uptake among PSP. Furthermore, positive perceptions of treatments are related to better treatment outcomes [18]. Second, the present findings provide guidance on how researchers and providers of ICBT should educate PSP about ICBT. Specifically, the findings suggest that adding a client story to an educational poster does not improve PSP's perceptions of ICBT. Additionally, few clients indicated that they had questions about ICBT after viewing the poster, suggesting that it provides a sufficient level of detail for most PSP. The questions participants asked were generally related to the logistics of ICBT, indicating that educational materials should clearly explain how ICBT is delivered. Male PSP and more experienced PSP may have less positive perceptions of ICBT; thus, it could be particularly important to design educational materials that appeal to PSP with these characteristics. Third, these findings provide guidance on how ICBT should be delivered to PSP. Participants demonstrated a greater preference for therapist-guided ICBT than self-guided ICBT. They indicated diverse preferences for therapist contact (e.g., once weekly, twice weekly, on demand), suggesting that providing clients with options may be more effective than giving all clients the same level of therapist contact. Participants also provided their perspectives on the disadvantages of ICBT (e.g., it could feel impersonal), which future research can help address.

Our research unit (PSPNET) recently conducted a study [8] in which we interviewed PSP about several topics, including their perspectives on ICBT. Despite some overlap in research questions and findings between the two studies, the recent study included only a qualitative analysis of the interviews with PSP, while the current study includes quantitative and qualitative analyses of survey data. Due in part to these methodological differences, the present study's findings expand upon those of the recent study in six important ways. First, $93 \%$ of participants in the present study indicated that they would use ICBT if they needed help with a mental health problem, which contrasts with the finding in our recent study that only $62 \%$ of participants believed that PSP would use ICBT. Second, we did not ask participants to rank their most preferred treatments in the recent study, and the finding that ICBT was participants' second most preferred treatment in the current study is novel. Third, the current study indicates that PSP have diverse preferences with respect to the regularity and frequency of therapist contact in ICBT. Fourth, we compared two means of informing PSP about ICBT in the current study, finding that adding a story did not result in more positive perceptions of ICBT. Fifth, we assessed for differences between PSP sectors in the current study, finding that there were no differences in perceptions among sectors. Sixth, we evaluated potential predictors of perceptions in the current study, finding that male and more experienced PSP may have less positive perceptions of ICBT.

\subsection{Strengths, Limitations, and Future Research}

This study has several strengths. First, it is unique, as it is one of the first to study PSP's perceptions of ICBT. Second, our sample included many participants reporting clinically significant mental health concerns, who represent the population most likely to benefit from ICBT for PSP. Third, our sample was diverse in certain respects (e.g., community size, level of education, age, relationship status, PSP sector), which serves to increase the generalizability of our findings. Fourth, this study benefited from a mixed-methods approach, and we were able to address our research questions through both quantitative and qualitative lenses.

This study also has several limitations. It is possible that results were influenced by sampling bias (i.e., participants' perceptions of ICBT may differ from those of PSP who decided not to participate). We cannot conclude that stories are not effective for educating PSP on ICBT; it is possible that a different story or an alternative method of presenting a story (e.g., video) would have had a greater impact on the participants' perceptions, particularly in light of evidence that stories presented in an audio or video format are more persuasive than stories relayed through text [23]. Additionally, nearly half of our 
sample reported having at least "a little knowledge" of ICBT before viewing the educational materials, and participants' preexisting perceptions of ICBT may have limited the impact of the educational materials. It is possible that additional factors we did not measure could have predicted participants' perceptions (e.g., confidence in using technology). Finally, our sample was drawn exclusively from the province of Saskatchewan, and our findings may not generalize to other provinces or countries.

The results of this study provide several directions for future research. Future research on PSP perceptions of ICBT could benefit from sampling outside of Saskatchewan to assess whether perceptions differ in other provinces or countries. Future research could further explore strategies for overcoming disadvantages. Relatedly, in our study, male PSP perceived ICBT as less credible than female PSP, and PSP with more experience perceived ICBT as less acceptable and anticipated that they would have lower adherence. Thus, future research could explore possible solutions to improve the perceptions of ICBT among male and more experienced PSP. Additional research could also help identify and evaluate alternative strategies (e.g., videos) for educating PSP about ICBT. Future research will be required to examine the effectiveness of ICBT for PSP and the perceptions of ICBT among PSP who have used it.

\section{Conclusions}

PSP experience high rates of mental health disorders, and ICBT is well situated to help expand access to treatment for PSP. After viewing educational materials on ICBT, PSP who participated in this study reported positive perceptions of ICBT and a preference for ICBT over most other sources of mental healthcare. Female participants perceived ICBT to be more credible than male participants did. More experienced PSP reported lower acceptability and anticipated adherence. There was no difference in perceptions between participants who received ICBT information from a poster and those who received ICBT information from a poster and a story. Participants in both conditions reported positive perceptions of ICBT, which supports the use of posters as a simple method of informing PSP about ICBT. Developers and providers of ICBT for PSP should be aware that our findings indicate that PSP have diverse preferences concerning the delivery of ICBT. Future research can extend these findings in several ways, such as by exploring strategies to improve perceptions of ICBT among groups with less favourable perceptions.

Author Contributions: Conceptualization, A.P.S., J.L.B., H.D.H.; methodology, H.C.M., A.P.S., J.L.B., H.D.H.; formal analysis, H.C.M., A.P.S., J.L.B., J.D.B., H.D.H.; investigation, H.C.M., A.P.S., J.L.B., H.D.H.; resources, H.C.M., A.P.S., H.D.H.; data curation, H.C.M., A.P.S., J.D.B.; writing-original draft preparation, A.P.S.; writing-review and editing, H.C.M., A.P.S., J.D.B., H.D.H.; visualization, H.C.M., A.P.S.; supervision, H.C.M., A.P.S., J.L.B., J.D.B., H.D.H.; project administration, A.P.S., H.D.H.; funding acquisition, H.D.H. All authors have read and agreed to the published version of the manuscript.

Funding: This research was conducted by PSPNET, which is funded by the Canadian Government's Ministry of Public Safety and Emergency Preparedness.

Acknowledgments: The authors would like to acknowledge members of the PSPNET team for their support with this project (e.g., review of the survey, assistance in preparing the study poster).

Conflicts of Interest: The authors declare no conflict of interest.

\section{Appendix A}

Educational poster describing ICBT 


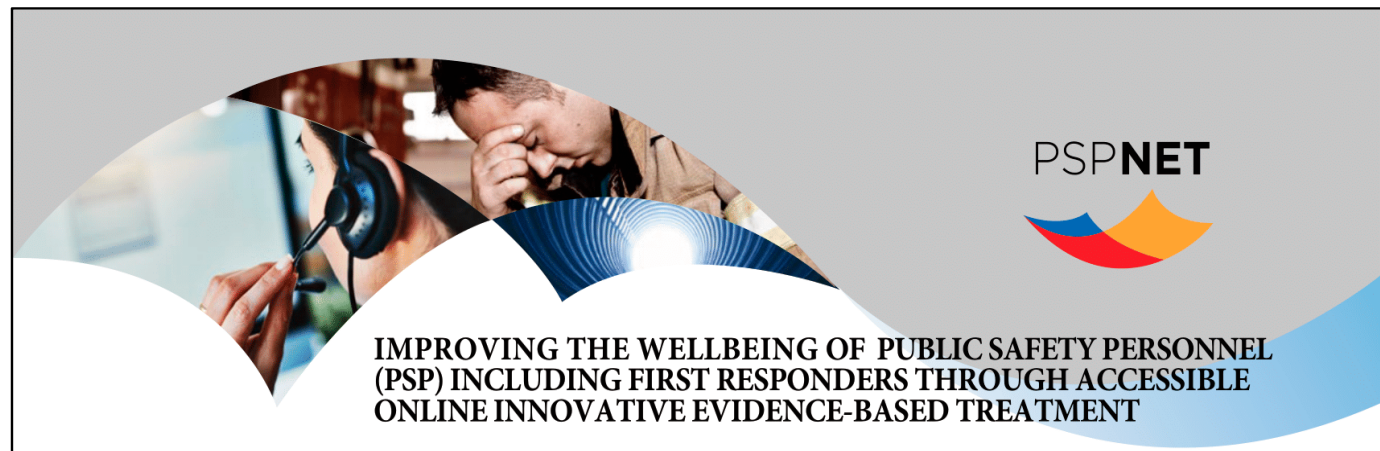

PSPNET is excited to announce the development of an Internet-delivered Cognitive Behaviour Therapy (ICBT) program specifically tailored for PSP including first responders, called the PSP Wellbeing Course.

\section{What is the ICBT PSP Wellbeing Course?}

- Evidenced-based treatment delivered over the Internet that provides the same content as face-toface cognitive behaviour therapy and has been found effective for treating symptoms of depression, anxiety and posttraumatic stress.

- Consists of 5 core lessons delivered through a secure website that clients typically complete over 8 weeks in a location and at a time that is convenient for them.

- Involves learning strategies to identify and manage feelings, thoughts, behaviours and physical sensations that can contribute to distress and difficulties with functioning.

- Includes online text and images that have been tailored to PSP. The information in each lesson can be downloaded and accessed at a later date.

- Clients receive suggested activities to facilitate learning after each lesson.

- Additional resources are available (e.g., for sleep, relationship problems).

- Clients receive automated emails as reminders to complete the program.

- Clients are assigned a designated trained therapis who is available by secure email or phone, one to two times per week as needed.

- Clients complete questionnaires during and after treatment to monitor improvements and evaluate outcomes.

\section{Who is PSPNET?}

- The Public Safety Personnel Internet-delivered Cognitive Behaviour Therapy (PSPNET) team is located at the University of Regina and part of the Canadian Institute of Public Safety Research and Treatment (CIPSRT) funded by Public Safety Canada.

- The PSPNET team is led by Dr. Heather Hadjistavropoulos, one of Canada's foremost leaders on ICBT.

- The team consists of both clinicians and researchers who have received training in ICBT for PSP.

Who can access PSPNET services?

- PSP including first responders

- Live in Saskatchewan

- Are 18 years of age or older

- Have access to a computer with Internet

- Are experiencing symptoms of anxiety, depression or post-traumatic stress injuries

- Are not seeking emergency services

- Are willing to periodically answer questionnaires (during treatment and at 8,16, 36, and 52 weeks) to help the PSPNET team evaluate the PSP Wellbeing Course

\section{How can I learn more?}

- Visit www.pspnet.ca and complete the online screening.

- Call 306-337-7233

This study has been approved

by the University of Regina

Research Ethics Board

\section{Appendix B}

Educational story describing a PSP's experience with ICBT 


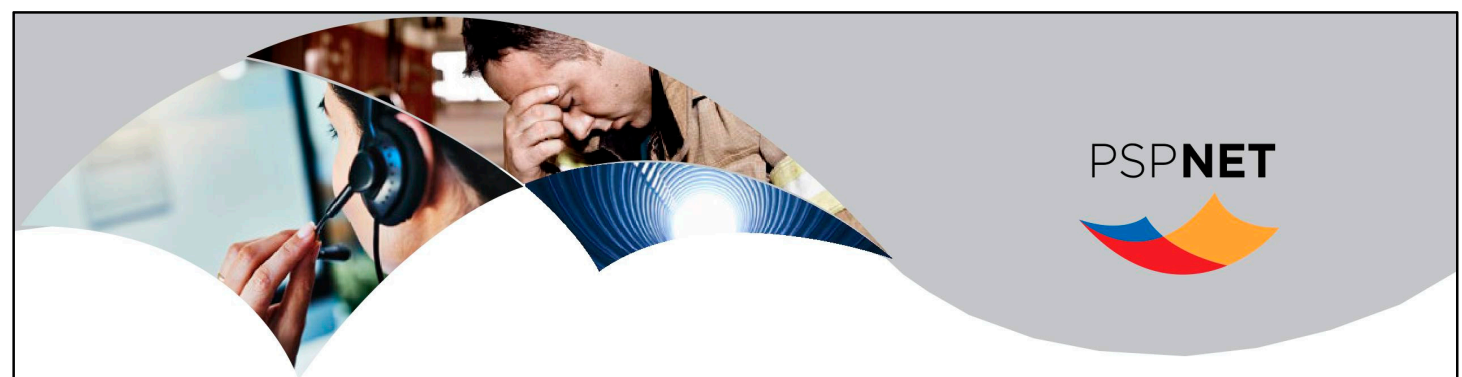

About Me...

$\mathrm{Hi}$, my name is Sam. I recently completed an Internet-delivered cognitive behaviour therapy program. I heard about the program through work. I wasn't sure this program would help, but thought it wouldn't hurt to give it a try. It seemed convenient. I could work on it from home when I had time, and it just felt like I had more control than if I went to see a face-to-face therapist. Looking back, I think it was a big step for me to enter the program. I always tried to manage things on my own, not really talking much to family and friends - about the stress of my job especially. Over the past several months, I started to notice things about myself that were not normal for me. When I got home from work, I wasn't interested in socializing or really doing anything. I wasn't interested in hanging out with my friends from outside of work because I felt like we had lost our connection. I found myself judging my friends and even my family when they would complain about little things. I preferred to come home, have a couple of drinks, and do my best to get my mind off of what I had seen that day. I was definitely more irritable, having trouble shutting off my thoughts at night and waking up after a few hours, and then I couldn't get back to sleep. I felt constantly on alert. Yes, I had to be alert at work, but I couldn't seem to come out of that mindset once work ended. It was exhausting.

My spouse noticed a change in me as well. I was snapping at her and naturally she was snapping right back. She quit asking me to do things with her. I noticed myself resenting that she didn't understand what my day was like and expected me to walk in the door and be "happy". At first, I thought I could just push through it, but things at home were getting progressively worse. In my line of work, I see and deal with some really messed up things - things that everyone else only reads about or sees on television. I'm not exactly sure when my attitude about people and life started to change. It was a gradual decline. I certainly remember coming into the field with enthusiasm and optimism. It wasn't just one call that pushed me to feel this way. It was an accumulation of calls over time. I just felt burdened, bitter, and run down. I could sense this at work too - some guys I had known for a long time were becoming jaded and negative. It was really all around me. I could sense this at work too-some guys I had known for a long time were becoming jaded and negative. It was really all around me.

\section{About the course ...}

To get into the course, I first completed an online screening and then a telephone screening. There were quite a few questions during the screening process, but I got the sense that my issues were being taken seriously, and that I was being heard and understood. Upon entering the program, I was given a username and password to access the online lessons. Each lesson contained pretty easy to read information, with suggested strategies to work on between lessons. There were also stories about other people who have jobs like mine and how they used the strategies. Some of their stories were similar to mine and some were different. There were also extra resources that I found helpful, for example on problem solving and sleep.

Once I started the program, I was immediately connected with an etherapist. I wasn't sure how much I would use the etherapist, but I ended up finding it really helpful to be able to write up an email to her when I had some thoughts - even if it was at 4am - it allowed me to work on things whenever I had time, knowing she would respond to messages two times each week. Weeks when I didn't email, she still reached out by email and provided encouragement. I liked knowing the therapist was there when I had questions or needed to share my thoughts. Some weeks we exchanged emails and a few times we talked by phone especially early in the program when I was having a harder time. I worked through all the materials in about 8 weeks but stayed connected with the therapist for another 4 weeks after that just to keep working on things. 


\section{What I took away ...}

This course really helped me to realize that anxiety and depression are normal experiences in life, but when they start to significantly impact your day-to-day, there are things you can and should do to manage them. I have seen and experienced a lot in my line of work-stuff that I've never talked about with anyone-stuff I'd rather just ignore. Over time, it really started to wear me down and impact my mood. Working through the lessons made me feel like there wasn't anything "wrong" with me, and that I needed some to take time to apply tools to help manage with the

Learning to break down my feelings into separate thoughts, physical sensations, and behaviour was an important first step. Breaking things down, made it a big more manageable. Learning how to be self-aware and use these tools in a practical way was tough for me. Lesson 2, talked about working through unhelpful thoughts and how to challenge them, which was difficult for me because I have always liked to push my thoughts away -I was able to work through my discomfort though, being provided tools to help me slow down my thoughts, and to learn how to challenge the negative things rolling through my mind. It especially took me a while to work on through my thoughts about needing to do more/better at work. When I have these thoughts now, I find myself asking "is this feasible?" "is this really in my control?" or "'what would be my colleagues actually say?"

It was also really helpful to think more about how my mind and body are connected. Terms like "underarousal" and "over-arousal" both rung true for me. Knowing how I could manage both of these through different techniques was helpful. For example, I read stories from past clients who talked about how symptoms of underarousal led them to withdraw from their social life. I knew I hadn't seen my friends in months, but I didn't really connect that to my depression before the course. I decided to use the activity scheduling tool from this course to help me be work on adding in activities to my life, especially to maintain connection with my friends and family. It may seem odd, but in addition to working on managing "under-arousal" I also at other times had to work on managing "over-arousal" like when coming off a crazy shift. Controlled breathing and grounding were two really simple but beneficial techniques I worked on and found so helpful that I wish I had known about them sooner.

Learning about unhelpful behaviours, I realized how my angry outbursts at my spouse were actually an avoidance behaviour. For example, when I snapped at her, she backed off and I would be left alone to zone out from my emotions. An activity in the course involving making a 'graded exposure ladder', intended to help me develop a plan to gradually introduce activities I had been avoiding to control my emotions. I started by writing down the things I was avoiding: various people, places, activities. One thing I was definitely avoiding was talking about my feelings. I know I can't talk to my spouse about everything I see on the job. But I also know I could be more open with her about what is going on and letting her know how she can support me without sharing all of the details. It took me a long time to make it to the top of the exposure ladder, and some days I still avoid things. At the same time, being aware of what I'm avoiding and realizing how that avoidance contributes to longer-term problems is critical.

\section{Where I am now ...}

By the end of the course, I was feeling way better than before. Although were still a lot of days when I felt "off" or when my symptoms flared up, I felt better able to manage these hard days. The final lesson in the course talked about how I shouldn't expect my symptoms to completely go away, that they can go up and down depending on what is happening in my life. That lesson also talked about how common relapses are and the typical causes of them, such as being run-down or tired, or even when you stop using the skills you learned. It gave me the heads up that the conditions of my job could easily expose me to relapse. However, having the awareness and tools to manage and address my thoughts and actions gives me hope - hope that I can deal with all life throws at me in a new and healthier way.

I really encourage everyone who experiences stress, anxiety, depression, irritability, post-traumatic stress to consider taking it. The only cost for taking the course is a few hours of your time each week, so if you're unsure about taking it (like I was), give it a try - what's there to lose? 


\section{References}

1. Carleton, R.N.; Afifi, T.O.; Turner, S.; Taillieu, T.; Duranceau, S.; LeBouthillier, D.M.; Hozempa, K. Mental disorder symptoms among public safety personnel in Canada. Can. J. Psychiatry 2018, 63, 54-64. [CrossRef] [PubMed]

2. Courtney, J.A.; Francis, A.J.; Paxton, S.J. Caring for the country: Fatigue, sleep and mental health in Australian rural paramedic shiftworkers. J. Commun. Health 2013, 38, 178-186. [CrossRef] [PubMed]

3. Maia, D.B.; Marmar, C.R.; Metzler, T.; Nóbrega, A.; Berger, W.; Mendlowicz, M.V.; Figueira, I. Post-traumatic stress symptoms in an elite unit of Brazilian police officers: Prevalence and impact on psychosocial functioning and on physical and mental health. J. Affect. Disord. 2007, 97, 241-245. [CrossRef] [PubMed]

4. Stanley, I.H.; Boffa, J.W.; Hom, M.A.; Kimbrel, N.A.; Joiner, T.E. Differences in psychiatric symptoms and barriers to mental health care between volunteer and career firefighters. Psychiatry Res. 2017, 247, $236-242$. [CrossRef]

5. Haugen, P.T.; Evces, M.; Weiss, D.S. Treating posttraumatic stress disorder in first responders: A systematic review. Clin. Psychol. Rev. 2012, 32, 370-380. [CrossRef]

6. Karaffa, K.M.; Koch, J.M. Stigma, pluralistic ignorance, and attitudes toward seeking mental health services among police officers. Crim. Justice Behav. 2016, 43, 759-777. [CrossRef]

7. Szeto, A.; Dobson, K.S.; Knaak, S. The road to mental readiness for first responders: A meta-analysis of program outcomes. Can. J. Psychiatry 2019, 64 (Suppl. 1), 18S-29S. [CrossRef]

8. McCall, H.C.; Beahm, J.D.; Fournier, A.K.; Burnett, J.L.; Carleton, R.N.; Hadjistavropoulos, H.D. Stakeholder perspectives on internet-delivered cognitive behavioural therapy for public safety personnel: A qualitative analysis. Can. J. Behav. Sci. 999. (in press).

9. Stanley, I.H.; Hom, M.A.; Joiner, T.E. A systematic review of suicidal thoughts and behaviors among police officers, firefighters, EMTs, and paramedics. Clin. Psychol. Rev. 2016, 44, 25-44. [CrossRef]

10. Andersson, G.; Carlbring, P.; Titov, N.; Lindefors, N. Internet interventions for adults with anxiety and mood disorders: A narrative umbrella review of recent meta-analyses. Can. J. Psychiatry 2019, 64, 465-470. [CrossRef]

11. Andersson, G. Internet-delivered psychological treatments. Annu. Rev. Clin. Psychol. 2016, 12, 157-179. [CrossRef] [PubMed]

12. Titov, N.; Dear, B.; Nielssen, O.; Staples, L.; Hadjistavropoulos, H.; Nugent, M.; Repål, A. ICBT in routine care: A descriptive analysis of successful clinics in five countries. Internet Interv. 2018, 13, 108-115. [CrossRef] [PubMed]

13. Hadjistavropoulos, H.D.; Nugent, M.M.; Alberts, N.M.; Staples, L.; Dear, B.F.; Titov, N. Transdiagnostic Internet-delivered cognitive behaviour therapy in Canada: An open trial comparing results of a specialized online clinic and nonspecialized community clinics. J. Anxiety Disord. 2016, 42, 19-29. [CrossRef]

14. Mccrone, P.; Knapp, M.; Proudfoot, J.; Ryden, C.; Cavanagh, K.; Shapiro, D.A.; Marks, I. Cost-effectiveness of computerized cognitive-behavioural therapy for anxiety and depression in primary care: Randomized controlled trial. Br. J. Psychiatry 2004, 185, 55-62. [CrossRef]

15. Musiat, P.; Goldstone, P.; Tarrier, N. Understanding the acceptability of e mental health: Attitudes and expectations towards computerized self-help treatment for mental health problems. BMC Psychiatry 2014, 11, 1-8. [CrossRef]

16. Wallin, E.E.K.; Mattssonm, S.; Olsson, E.M.G. The preference for Internet-based psychological interventions by individuals without past or current use of mental health treatment delivered online: A survey study with mixed-methods analysis. J. Med Internet Res. 2016, 3, e25. [CrossRef]

17. March, S.; Day, J.; Ritchie, G.; Rowe, A.; Gough, J.; Hall, T.; Ireland, M. Attitudes toward e-mental health services in a community sample of adults: Online survey. J. Med Internet Res. 2018, 20, e59. [CrossRef]

18. Constantino, M.J.; Arnkoff, D.B.; Glass, C.R.; Ametano, R.M.; Smith, J.Z. Expectation. J. Clin. Psychol. 2011, 67, 184-192. [CrossRef]

19. Mitchell, N.; Gordon, P.K. Attitudes towards computerized CBT for depression amongst a student population. Behav. Cogn. Psychother. 2007, 35, 421-430. [CrossRef]

20. Krakauer, R.L.; Stelnicki, A.M.; Carleton, R.N. Examining Mental Health Knowledge, Stigma, and Service Use Intentions Among Public Safety Personnel. Front. Psychol. 2020, 11, 949. [CrossRef]

21. Blenkiron, P. Stories and analogies in cognitive behaviour therapy: A clinical review. Behav. Cogn. Psychother. 2005, 33, 45-59. [CrossRef] 
22. Mattila, A.S. The role of narratives in the advertising of experiential services. J. Serv. Res. 2000, 3, 35-45. [CrossRef]

23. Shen, F.; Sheer, V.C.; Li, R. Impact of narratives on persuasion in health communication: A meta-analysis. J. Advert. 2015, 44, 105-113. [CrossRef]

24. Public Safety Canada Supporting Canada's Public Safety Personnel: An Action Plan on Post-Traumatic Stress Injuries. Available online: https://www.publicsafety.gc.ca/cnt/rsrcs/pblctns/2019-ctn-pln-ptsi/index-en.aspx (accessed on 26 June 2020).

25. Dear, B.F.; Staples, L.G.; Terides, M.D.; Karin, E.; Zou, J.; Johnston, L.; Titov, N. Transdiagnostic versus disorder-specific and clinician-guided versus self-guided internet-delivered treatment for generalized anxiety disorder and comorbid disorders: A randomized controlled trial. J. Anxiety Disord. 2015, 36, 63-77. [CrossRef]

26. Löwe, B.; Wahl, I.; Rose, M.; Spitzer, C.; Glaesmer, H.; Wingenfeld, K.; Brähler, E. A 4-item measure of depression and anxiety: Validation and standardization of the Patient Health Questionnaire-4 (PHQ-4) in the general population. J. Affect. Disord. 2010, 122, 86-95. [CrossRef]

27. Lang, A.J.; Stein, M.B. An abbreviated PTSD checklist for use as a screening instrument in primary care. Behav. Res. Ther. 2005, 43, 585-594. [CrossRef]

28. Milosevic, I.; Levy, H.C.; Alcolado, G.M.; Radomsky, A.S. The treatment acceptability/adherence scale: Moving beyond the assessment of treatment effectiveness. Cogn. Behav. Ther. 2015, 44, 456-469. [CrossRef]

29. Wilson, C.J.; Deane, F.P.; Ciarrochi, J.V.; Rickwood, D. Measuring help seeking intentions: Properties of the general help seeking questionnaire. Can. J. Couns. 2005, 39, 15-28. [CrossRef]

30. Devilly, G.J.; Borkovec, T.D. Psychometric properties of the credibility/expectancy questionnaire. J. Behav. Ther. Exp. Psychiatry 2000, 31, 73-86. [CrossRef]

31. Thompson-Hollands, J.; Bentley, K.H.; Gallagher, M.W.; Boswell, J.F.; Barlow, D.H. Credibility and outcome expectancy in the unified protocol: Relationship to outcomes. J. Exp. Psychopathol. 2014, 5, 72-82. [CrossRef]

32. Apolinário-Hagen, J.; Vehreschild, V. E-mental health—“nice to have" or "must have"? Exploring the attitudes toward e-mental health in the general population. In Proceedings of the 3rd IPLeiria's International Health Congress, Leiria, Portugal, 6-7 May 2016. [CrossRef]

33. Elo, S.; Kyngäs, H. The qualitative content analysis process. J. Adv. Nurs. 2008, 62, 107-115. [CrossRef]

34. Faul, F.; Erdfelder, E.; Lang, A.G.; Buchner, A. G*Power 3: A flexible statistical power analysis program for the social, behavioral, and biomedical sciences. Behav. Res. Methods 2007, 39, 175e191. [CrossRef]

35. Soucy, J.N.; Hadjistavropoulos, H.D. Treatment acceptability and preferences for managing severe health anxiety: Perceptions of internet-delivered cognitive behaviour therapy among primary care patients. J. Behav. Ther. Exp. Psychiatry 2017, 57, 14-24. [CrossRef]

36. Peynenburg, V.A.; Mehta, S.; Hadjistavropoulos, H.D. Postsecondary student perceptions and preferences for the treatment of depression and anxiety: Comparison of internet-delivered cognitive behaviour therapy to face-to-face cognitive behaviour therapy and medication. Can. J. Behav. Sci. /Rev. Can. Sci. Comport. 2020, 52, 220-230. [CrossRef]

37. Apolinário-Hagen, J.; Fritsche, L.; Bierhals, C.; Salewski, C. Improving attitudes toward e-mental health services in the general population via psychoeducational information material: A randomized controlled trial. Internet Interv. 2018, 12, 141-149. [CrossRef]

38. Eisenberg, D.; Golberstein, E.; Gollust, S.E. Help-seeking and access to mental health-care in a university student population. Med. Care 2007, 45, 594-601. [CrossRef]

39. Schröder, J.; Berger, T.; Björn, M.; Lutz, W.; Hautzinger, M.; Spath, C.; Moritz, S. Attitudes towards internet interventions among psychotherapists and individuals with mild to moderate depression symptoms. Cogn. Ther. Res. 2017, 41, 745-756. [CrossRef]

40. Moskalenko, M.Y.; Hadjistavropoulos, H.D.; Katapally, T.R. Barriers to patient interest in Internet-based cognitive behavioral therapy: Informing e-health policies through quantitative analysis. Health Policy Technol. 2020, 9, 139-145. [CrossRef]

41. Apolinário-Hagen, J.; Vehreschild, V.; Alkoudmani, R.M. Current views and perspectives on e-mental health: An exploratory survey study for understanding public attitudes toward internet-based psychotherapy in Germany. JMIR Ment. Health 2017, 4, e8. [CrossRef]

(C) 2020 by the authors. Licensee MDPI, Basel, Switzerland. This article is an open access article distributed under the terms and conditions of the Creative Commons Attribution (CC BY) license (http://creativecommons.org/licenses/by/4.0/). 